\title{
A sustentabilidade ambiental como direcionador estratégico ao processo de reindustrialização no Brasil
}

\author{
Pedro dos Santos Portugal Júnior * \\ Bastiaan Philip Reydon ** \\ Nilton dos Santos Portugal ${ }^{* * *}$
}

\begin{abstract}
Resumo
O presente trabalho objetiva apresentar uma proposta de direcionamento político e econômico para a indústria brasileira, voltando-se para um contexto de sustentabilidade ambiental como posicionamento estratégico na competitividade internacional, servindo assim como uma alternativa de combate ao atual processo de desindustrialização no país. O Brasil deveria aproveitar sua liderança em certos ramos sustentáveis como a produção energética e de sua disponibilidade de recursos naturais para redirecionar o processo industrial via uma política econômica que integre a questão ambiental e a necessidade de reindustrializar a economia. Para tanto, a ação do Estado é primordial como indutor e regulador do processo, bem como, sendo um dos principais financiadores deste projeto, conciliando uma nova política industrial ambientalmente sustentável com mudanças na política monetária e cambial, para que a ação possa ser realmente efetiva.
\end{abstract}

Palavras-chave: Desindustrialização; Reindustrialização sustentável; Competitividade internacional; Políticas industriais.

\begin{abstract}
Environmental sustainability as strategic direction to be taken in the re-industrialization process in Brazil

This work presents a proposal for political and economic direction to be taken in Brazilian industry. This proposal suggests going back to a time of of environmental sustainability as a strategic position in international competitiveness, which would serve as an alternative in combatting the current process of deindustrialization in the country. Brazil should leverage its leadership in certain areas such as sustainable energy production and availability of natural resources in order to redirect the industrial process through the use of an economic policy that integrates environmental issues and the need to reindustrialize the economy. For this to occur, government action is paramount and must initiate and regulate the process. The state must also provide the main financial support of this project, which would combine a new environmentally sustainable industrial policy with changes in monetary and exchange policy, so that actions taken can be truly effective.
\end{abstract}

Keywords: Deindustrialization; Sustainable re-industrialization; International competitiveness; Industrial policies.

JEL Q56, Q58, O25.

${ }^{*}$ Professor do Centro Universitário do Sul de Minas (Unis-MG), Brasil. E-mail: pedrorotaract@hotmail. com.

** Professor e pesquisador do NEA - IE - Unicamp. E-mail: < basrey@eco.unicamp.br>

*** Professor do Centro Universitário do Sul de Minas (Unis/MG), Brasil. E-mail: nilton@unis.edu.br. 


\section{Introdução}

O Brasil, a partir dos anos 1980 e 1990, passou a apresentar uma sensível queda da participação do setor industrial nos dados agregados de produção e geração de emprego, seja em termos relativos ou absolutos. Esse fato deflagrou um processo denominado desindustrialização na economia brasileira, muito comum em economias mais avançadas, porém com contornos completamente diferenciados na realidade local, por ocorrer no momento em que a indústria nacional ainda não se encontrava totalmente estruturada e desenvolvida.

De acordo com Oreiro e Feijó (2010); Rowthorn e Ramaswany (1999); Tregenna (2009), a definição "clássica" de desindustrialização foi apresentada como sendo uma redução persistente da participação do emprego industrial no emprego total de um país ou região. Recentemente, redefiniu-se de forma mais ampla o conceito "clássico" de desindustrialização como sendo uma situação na qual tanto o emprego industrial como o valor adicionado da indústria reduzem-se como proporção do emprego total e do Produto Interno Bruto (PIB) respectivamente.

Para Souza (1999), a queda de participação do emprego industrial no emprego total pode ser considerada um fato normal da maturidade econômica, devido à mudança tecnológica que tende a substituir o trabalho pelo capital na indústria.

De acordo com Oreiro e Feijó (2010), no entanto, a análise do caso brasileiro apresenta duas correntes com visões antagônicas do processo de desindustrialização:

- Os economistas da linha keynesiano-desenvolvimentistas, os quais defendem a tese de que a economia brasileira vem passando por um processo de desindustrialização nos últimos vinte anos, causado pela combinação perversa entre abertura financeira, alta taxa de juros, valorização dos termos de troca em favor das commodities e câmbio apreciado ${ }^{1}$.

- Os economistas da corrente ortodoxa, cuja afirmação é de que as transformações pelas quais a economia brasileira passou nas últimas décadas não tiveram um efeito negativo sobre a indústria e a apreciação do câmbio real resultante dessas reformas favoreceu a indústria ao permitir a importação de máquinas e equipamentos tecnologicamente mais avançados e isso permitiu a modernização do parque industrial brasileiro, consequentemente, a expansão da própria produção industrial

Mais importante, todavia, do que discutir o tipo de desindustrialização no Brasil é determinar a postura estratégica da indústria brasileira no mercado mundial e como realizar sua (re)inserção no processo de competitividade sistêmica em um contexto global.

(1) Mesmo os autores da linha heterodoxa não são unânimes em afirmar se o Brasil realmente passou ou está passando por um processo de desindustrialização nem qual tipo de processo desindustrializante pode ter ocorrido. Para uma discussão mais profunda e atual, vide Laplane e Sarti (2006) Sarti e Hiratuka (2011). 
Esse contexto é, atualmente, bastante influenciado pelas questões ambientais e a busca pela sustentabilidade social e ambiental, impactando diretamente os processos decisórios dos agentes econômicos. Também no mesmo contexto, surgem duas concepções opostas (São Paulo, 2010):

- Os desenvolvimentistas do século XX, conservadores, os quais acham que a redução de gases de efeito estufa e dos impactos ambientais irá provocar uma diminuição do ritmo de crescimento econômico do país;

- Os desenvolvimentistas do século XXI, progressistas, os quais acreditam que a postura de diminuição dos impactos ambientais possibilitaria ao Brasil uma mudança estratégica para uma economia de baixo carbono, conquistando novos mercados com viés ambiental.

Sendo assim, o presente artigo objetiva apresentar uma proposta de reindustrialização brasileira, em um contexto de sustentabilidade ambiental como direcionador estratégico desse processo.

De forma específica, o estudo busca apresentar primeiro e de forma bem objetiva as definições teóricas do processo de desindustrialização, bem como algumas evidências empíricas de sua possível ocorrência no Brasil. Posteriormente, apresentam-se questões que permitem aprofundar a possibilidade de um processo de reindustrialização sustentável no Brasil e seus possíveis benefícios econômicos e estratégicos nos âmbitos macro e microeconômico.

Um estudo assim é justificado pelo fato de o Brasil passar atualmente por um processo de determinação de seu posicionamento estratégico como um importante player no mercado internacional. Enquanto outros países emergentes como China e Índia já demonstraram de maneira clara seus objetivos estratégicos, o Brasil ainda não se posicionou de forma evidente, o que pode levar a indústria local a sofrer perdas competitivas graves.

A técnica adotada foi de pesquisa documental e bibliográfica, portanto um estudo de caráter exploratório e teórico, tendo por base trabalhos publicados pelo Instituto de Estudos para o Desenvolvimento Industrial(IEDI), revistas especializadas, estudos, tese e artigos especializados na área. Para tanto, o trabalho divide-se em quatro partes incluindo introdução, capítulo um que trata uma breve consideração sobre a desindustrialização no Brasil apontando alguns dados e análises sobre o tema, o segundo capítulo que aborda a proposta de reindustrialização sustentável, sendo esse o foco principal do presente estudo e, por fim, as considerações finais.

\section{A questão da desindustrialização no Brasil}

Antes de abordar a proposta de reindustrialização sustentável torna-se importante entender algumas conceituações sobre desindustrialização, bem como a dinâmica histórica e estrutural brasileira que provocou esse processo. 
Assim, o presente capítulo pretende abordar, de forma objetiva, duas questões importantes: primeiro, as definições e tipos de desindustrialização e, posteriormente, a análise de algumas causas e consequências do fenômeno desindustrializante brasileiro.

\subsection{Desindustrialização: definições e tipos}

Para o IEDI (2005) e Souza (1999), a desindustrialização consiste em um processo de declínio da produção e do emprego industrial em valores absolutos ou em relação à produção e emprego total. Trata-se de um processo normal na evolução das economias no atingimento de sua maturidade, ocorrendo em etapas onde, no início do processo de expansão econômica, a industrialização provoca uma queda da participação da agricultura e do emprego agrícola na produção total e, posteriormente, a evolução do setor terciário diminui a participação da indústria na economia como um todo.

Torna-se importante salientar que, ao se tratar sobre desindustrialização, o foco de análise converge para a indústria de transformação, pois conforme IEDI (2005, p. 8) "é a classe industrial que mais se aproxima do conceito de 'indústria manufatureira', em torno ao qual se aplicam as teses de desindustrialização".

O principal desafio dos países é atingir o estado de maturidade econômica sem perder participação no mercado mundial, também não comprometer o processo de crescimento e desenvolvimento econômico, haja visto que a indústria tem um papel importante na geração de investimentos, produtividade, economia de escala e inovações.

Existem variados tipos de desindustrialização, porém as classificações mais evidentes são conforme IEDI (2005) e Comin (2009):

- desindustrialização madura: quando ocorre a queda relativa do emprego industrial em economias avançadas, podendo ser interpretada como uma etapa do desenvolvimento que resulta do aprofundamento da divisão do trabalho;

- desindustrialização prematura: quando a participação da indústria na economia cai antes do atingimento da maturidade econômica do país;

- desindustrialização precoce: quando o próprio país abre mão do papel da dinâmica industrial como motor do processo de crescimento econômico;

- desindustrialização relativa: ocorre em função de uma especialização de alguns setores industriais, sendo assim, o dinamismo industrial passa a depender de um menor número de atividades;

- desindustrialização localizada: quando alguns setores específicos da indústria perdem importância ao longo dos anos, em função principalmente da falta de investimentos, perda de competitividade ou de mercado. 
- desindustrialização negativa: consiste na redução da importância do setor industrial em função de um contexto de desaceleração generalizada do crescimento econômico, fruto principalmente de políticas macroeconômicas adversas ao processo de desenvolvimento produtivo.

A relação de tipos de desindustrialização não esgota a discussão sobre esse assunto, porém já torna possível o entendimento do tema para a continuidade do estudo.

\subsection{O processo desindustrializante brasileiro: algumas questões e debates}

Definir o tipo de desindustrialização pelo qual o Brasil passa desde os anos 1980 é uma tarefa difícil, porém o mais evidente de ser analisado são as possíveis causas desse processo as quais podem ser enumeradas da seguinte forma, segundo o IEDI (2005), Comin (2009), Cano e Silva (2010) e Kleber (2010).- A crise inflacionária dos anos 1980 e as políticas de contenção aplicadas para evitar-se a hiperinflação, que influenciaram de maneira negativa, dentre outras coisas, a própria formação de expectativas para investimentos produtivos;

- A abertura comercial realizada a partir do início dos anos 1990 sem uma estruturação e preparação das empresas locais, que careciam de reformas institucionais (tributária, burocrática etc.) e infraestrutura básica de qualidade, fatores estes que elevavam o "Custo Brasil"”. A tarifa média de importação caiu de 57,5\% em 1987, para 30,5\% em 1990 e para $11,2 \%$ em 1994, estando em 2008 na casa de 13,6\%;

- A implantação do Plano Real com uma sobrevalorização da moeda nacional que seria revertida somente em 1999, impactando diretamente a competitividade dos produtos brasileiros no mercado internacional, além de inibir o investimento produtivo. O período inicial do plano foi decisivo para o baixo dinamismo industrial ao deprimir seu crescimento, o que já vinha ocorrendo em momentos anteriores. Somam-se a isso os processos de desestatização realizados sem uma estratégia de política industrial bem estabelecida;

- A sucessão de uma série de crises na segunda metade dos anos 1990 que prejudicaram a realização de investimentos produtivos e a formação de expectativas pelos agentes;

- Também, a partir dos anos 1990, os sucessivos processos de terceirização de certas atividades, antes desenvolvidas na própria indústria, contribuíram para a diminuição do nível de empregos no setor secundário. Entre 2006 e 2008, mais da metade das empresas industriais brasileiras contrataram serviços terceirizados.

(2) Os formuladores da política econômica do país, seguindo os pressupostos do Consenso de Washington, acreditavam que as forças de mercado seriam capazes de promover a modernização produtiva, a melhoria da competitividade e o aporte necessário de capital, tecnologia e conhecimento (Cano; Silva, 2010). 
Fatos bem recentes podem ser apontados também como causas desse processo desindustrializante, segundo Kleber (2010):

- A crise financeira de 2008 que diminuiu as importações de países da Europa e Estados Unidos;

- A competição mais aguda dos manufaturados chineses com relação aos brasileiros, principalmente em países da América do Sul e, também, no mercado interno;

- A valorização do Real que, entre 2004 e o primeiro semestre de 2010, atingiu a marca de 40,6\% (sendo a maior valorização monetária do mundo), enquanto outros países emergentes tiveram uma valorização menor ou até mesmo desvalorizaram suas moedas.

- O pouco avanço na agenda de acordos comerciais nos últimos anos, principalmente, com países desenvolvidos.

Baseado em tais causas, pode-se relacionar algumas consequências para o setor industrial brasileiro, sem, contudo, pretender esgotar o assunto.

Comin (2009) afirma que, tomando 1987 como referência do último ano antes do início da abertura comercial, a indústria de transformação perdeu $6 \%$ de participação na estrutura de geração de valor adicionado da economia brasileira (de $40 \%$ para cerca de $34 \%$ ), fruto exatamente da combinação de acelerada abertura comercial com valorização cambial, provocando um processo significativo de desindustrialização.

Para Souza (1999), a redução da demanda externa por manufaturados, em virtude de uma menor eficiência produtiva, ou taxa de câmbio valorizada, desencadeia efeitos negativos sobre os setores interligados, diminuindo o nível de produção industrial. Assim, tal diminuição reduz igualmente o nível de investimentos e a taxa de inovação tecnológica.

Outra consequência é apresentada por Lima (2010) em que a combinação entre a valorização das commodities e a redução do peso dos produtos industrializados na pauta de exportações do Brasil provocou, no ano de 2010, alterações no ranking dos principais municípios exportadores do país. São Paulo, que até 2009 era a primeira colocada, caiu para a terceira posição, perdendo espaço para Angra dos Reis - RJ (em virtude o petróleo) e Parauapebas - PA (em virtude do minério de ferro). Municípios que possuíam uma pauta de exportação diversificada e baseada na indústria de transformação apresentaram queda nesse ranking, como por exemplo, São José dos Campos - SP que caiu de terceiro para o sexto lugar.

Corrobora com tal fato a afirmativa de Guimarães (2010) de que houve uma mudança na pauta de exportação do país, ocorrido pelo fato de que a indústria brasileira 
tem exportado menos e importado cada vez mais itens tradicionalmente produzidos no Brasil e, limitada por câmbio, impostos e custos, perdido competitividade no exterior. Em alguns setores de maior valor tecnológico agregado, há casos em que a exportação foi simplesmente abandonada dos negócios porque deixou de ser vantajosa para a empresa.

Estudo divulgado pelo IEDI (2011) demonstra que a balança comercial da indústria de transformação apresentou em 2010 um déficit de US\$ 34,76 bilhões, sendo que para 2011 a previsão era de que este déficit poderia ser próximo de US\$ 50 bilhões.

Com relação à participação da indústria no PIB, Lavoratti (2010) afirma que o setor atingiu seu pico no final dos anos 1970 quando respondia por $37 \%$ das riquezas do país, oscilando bastante após esta época e atingindo 30,1\% em 2004 e $25,4 \%$ em 2009. Apesar de certo crescimento recente, a indústria avançou menos que os demais setores.

Comin (2009) afirma que atualmente, em detrimento da indústria de transformação, a indústria extrativa mineral passou a ser o componente mais dinâmico do PIB brasileiro, em virtude inclusive do crescimento da indústria de petróleo e gás e pela ampliação da produção de minério de ferro.

Outros autores, no entanto, afirmam que, a partir de 2004, com o surgimento de certos planos como o Programa de Aceleração do Crescimento (PAC) em 2007, juntamente à Política Industrial, Tecnológica e de Comércio Exterior (PITCE) de 2004 a 2007 e à Política de Desenvolvimento Produtivo (PDP) de 2008 a 2010 ocorreu melhoria e expansão da indústria de transformação no Brasil, ainda não sentida totalmente em virtude da crise de 2008. Tais políticas surgiram em torno de uma participação mais efetiva do Estado no processo de investimento e incentivos ao setor industrial e ao consumo, aliadas a uma série de medidas anticíclicas (Mercadante, 2010).

Nesse contexto, cabe destacar a afirmação de Sarti e Hiratuka (2011) de que, no início, o retorno do dinamismo industrial esteve ligado ao aumento da demanda doméstica por bens de consumo, principalmente duráveis e semiduráveis. Já, em um segundo momento, o vetor do dinamismo expandiu-se para o investimento, refletindo-se na expansão da formação bruta de capital a partir de 2006, sobretudo de 2007.

Assim, a indústria brasileira apresentou uma capacidade de reação, possibilitando a retomada de investimentos, expansão da produção e, principalmente, interrompendo o processo de desindustrialização relativa a partir do adensamento de algumas cadeias produtivas. 
Cabe destacar, ainda de acordo com Sarti e Hiratuka (2011), que há indícios de que as medidas fiscais, monetárias e financeiras, tomadas a partir do contexto da crise mundial, tiveram efeito positivo, de forma que ao final de 2009 e início de 2010 já haveria sinais de que a economia brasileira teria retomado seu dinamismo com base em um padrão similar ao do período pré-crise.

Veem-se, então, diferentes abordagens e interpretações sobre a questão da desindustrialização no Brasil, ou seja, seus tipos, causas e consequências, bem como sobre os direcionamentos para o comportamento futuro do setor industrial na economia brasileira.

Cabe, todavia, salientar que o momento pede uma nova abordagem sobre o processo de reindustrialização no Brasil, o qual busque uma proposta de reinserção do setor industrial brasileiro na competitividade internacional.

\section{Reindustrialização sustentável como estratégia: análises e evidências de uma proposta}

Conforme já explicitado na introdução, o objetivo geral do estudo é apresentar uma proposta para a reindustrialização brasileira, definindo a questão da sustentabilidade ambiental como o ponto chave do posicionamento estratégico. Sendo assim, neste capítulo apresenta-se tal proposta, bem como algumas evidências que fundamentam a questão.

O desenvolvimento sustentável apresenta três fundamentos básicos: econômico, social e ambiental, tendo sido definidos a partir do Relatório Brundtland, sendo este fruto de um trabalho da Comissão Mundial sobre Meio Ambiente e Desenvolvimento da Organização das Nações Unidas iniciado em 1983 e publicado em 1987 (Cavalcanti, 1996).

A partir disso, surgem vários direcionamentos sobre a sustentabilidade com diferentes abordagens: social, ambiental, política, econômica, cultural entre outras. Para o desenho da proposta do trabalho, no entanto, o foco principal será na sustentabilidade ambiental, ou seja, o emprego dos recursos naturais de forma sustentável que, conforme Daly e Farley (2004), deve utilizar os recursos renováveis de acordo com sua capacidade de renovação e os recursos não renováveis conforme a capacidade do meio ambiente em absorver os resíduos gerados por seu uso.

Atualmente, a questão ambiental tornou-se uma diretriz importante para as empresas, levando a processos de tomada de decisão que internalizam os impactos causados ao meio ambiente como uma forma de evitar problemas relativos a multas, investigações e outras ocorrências que venham a denegrir a imagem da empresa. 
Certos segmentos já compreenderam, contudo, que a questão da sustentabilidade ambiental pode ser usada também como uma estratégia para obter vantagem competitiva no mercado.

Reydon et al. (2007) afirmam que a revisão do processo produtivo na busca de diminuir os impactos ambientais pode acarretar oportunidades de redução de custos e ganhos de competitividade. Tal fato ficou denominado como "hipótese de Porter", ainda defensor das normas ambientais, as quais, quando bem estruturadas e aplicadas, podem estimular o desenvolvimento de inovações que possibilitem às empresas adequarem-se a elas e, ao mesmo tempo, obterem competitividade.

Percebe-se uma mudança de paradigma do sistema capitalista nesse sentido, saindo de um direcionamento fordista de produção para um posicionamento baseado na Tecnologia da Informação e da Comunicação. Em tal contexto, pode-se apresentar uma comparação entre os dois paradigmas conforme o Quadro 1.

Quadro 1

Comparação entre os paradigmas fordista e da tecnologia da informação e comunicação

\begin{tabular}{|l|l|}
\hline Fordista & Tecnologia da Informação e Comunicação \\
\hline Intensivo em energia & Intensivo em informação \\
\hline Produtos padronizados & "Customerizado" \\
\hline Mix de produtos & Muda mix produtos \\
\hline Planta/equipamento específico & Sistema de produção flexível \\
\hline Empresas individuais & Redes de produção \\
\hline Estrutura hierarquizada & Estrutura horizontal \\
\hline Produto com serviços & Serviço com produto \\
\hline Centralização & Distribuiçăo inteligente \\
\hline Governo-proprietário e planejador & Governo-coordenador e regulador \\
\hline
\end{tabular}

Fonte: Freeman(1992) adaptado pelos autores.

Essa visão microeconômica permite ampliar a análise da questão, focando no âmbito macroeconômico e de política econômica. Assim, um direcionamento de política industrial voltado para a sustentabilidade pode levar um segmento e/ou setor econômico de um país a obter vantagem competitiva, ampliando e fortalecendo sua posição de mercado como importante player mundial.

Poucos países fizeram da questão ambiental um fator importante em suas decisões políticas e econômicas. Os casos mais evidentes são Alemanha, Reino Unido, Coreia do Sul, os países Nórdicos e o estado americano da Califórnia, porém, com exceção dos Países Nórdicos ${ }^{3}$, nenhum outro fez dessa decisão um evidente posicionamento estratégico de competitividade.

(3) Suécia, Noruega e Finlândia desenvolveram profundas capacidades tecnológicas inovadoras em setores relacionados a recursos naturais como mineração, florestal, celulose e papel, óleo e gás (Figueiredo, 2011). 
Angus Maddison afirma que as grandes fases do desenvolvimento capitalista decorrem de choques sistêmicos específicos e reorientações das políticas governamentais que nada têm a ver com a sinuosidade dos movimentos "ondulatórios" dos ciclos econômicos, conforme a concepção de Veiga (1997). Pode-se afirmar,

portanto, que a busca pela sustentabilidade ambiental tem o potencial de determinar esse choque sistêmico e tornar-se uma reorientação de política econômica e industrial, independente da fase do ciclo que a economia esteja passando.

A probabilidade de que as mudanças climáticas não mitigadas provavelmente superem a capacidade de adaptação dos sistemas naturais e humanos, bem como comprometam a geração de serviços ecossistêmicos, leva à necessidade de uma descarbonização dos sistemas econômicos, justificando, assim, os investimentos em novas formas de produção (São Paulo, 2010).

A inação pode ter consequências econômicas graves em um futuro próximo, pois, de acordo com Krugman (2010), países que não aceitam reduzir suas emissões de $\mathrm{CO}_{2}$, bem como outros processos que impactam o meio ambiente, poderão ter seus produtos sobretaxados proporcionalmente aos impactos ambientais de sua fabricação. A partir do momento que grandes players mundiais aplicarem essas sobretaxas, o restante dos países passará a seguir tal fato, somando-se a isso as pressões de regulamentação por parte de organismos internacionais ${ }^{4}$. Ademais, segundo Rose e Kunze (2009), existem expectativas de crescimento do mercado de produtos e serviços ambientalmente corretos de 6,5\% ao ano no período de 2010 a 2020.

A posição brasileira na questão da sustentabilidade como um direcionamento estratégico de concorrência é ambígua. Afinal, ao mesmo tempo em que se tornou um líder mundial na utilização de energia renovável, principalmente hidrelétrica, segundo Rose e Kunze (2009) e realizou maciços investimentos em inovações tecnológicas ambientais corretas em setores como o florestal e de celulose e papel, de acordo com Figueiredo (2011), continua tendo 70,3\% de suas exportações industriais focadas em produtos de alto potencial poluidor ${ }^{5}$, conforme Lustosa (2008). Tal fato pode determinar graves consequências no posicionamento e competitividade internacional da indústria brasileira à medida que os países passem

(4) Um exemplo é a possibilidade de criação nos próximos anos de um Selo Verde Europeu para Mineração, semelhante ao já existente para produtos químicos, que verificará todo o processo do produto mineral, desde sua extração até o transporte ao comprador. (Para melhores informações, vide Portugal Júnior et al. (2010)). Pode-se citar também a discussão, no âmbito da UNFCC (Quadro das Nações Unidas sobre Mudanças Climáticas) sobre a regulamentação de Ações Nacionalmente Apropriadas de Mitigação (Namas) e dos Mecanismos de Redução de Emissões por Desmatamento e Degradação Florestal (Redd) (Dias, 2010).

(5) Referente a dados de 2007 e conforme a classificação baseada no licenciamento ambiental de empreendimentos industriais. 
a adotar regulamentações ambientais mais exigentes sobre os produtos importados, conforme explicitado anteriormente.

Cumpre, assim, salientar a importância de estabelecer-se a sustentabilidade ambiental como um direcionador estratégico dos produtos industriais brasileiros via política econômica e industrial, como uma forma de restabelecer a importância da indústria na economia nacional e, ao mesmo tempo, antecipar ao mercado no processo de competitividade verde.

Para Figueiredo (2011), uma combinação bem estruturada entre abundância de recursos naturais e esforços sistemáticos e competentes em inovações ambientalmente corretas pode resultar em liderança tecnológica e comercial em nível internacional.

Importante determinar que é necessário haver uma conjugação entre as políticas econômicas do país, pois, conforme Cano e Silva (2010, p. 8), "as estratégias de desenvolvimento industrial não se fazem apenas com políticas industriais explícitas. Por melhor que seja seu desenho, deve contar com políticas macroeconômicas compatíveis". Assim, torna-se necessário uma revisão das bases de sustentação dos fundamentos macroeconômicos atuais, inclusive no que se relaciona a um regime de câmbio flutuante que sobrevaloriza a moeda local em relação ao dólar, comprometendo a competitividade dos produtos industrializados locais, bem como uma política monetária demasiado contracionista, com altas taxas de juros que inibem o investimento em novas formas de produção ambientalmente corretas. Somam-se a essa questão política as propostas apresentadas por Jackson (2009), para a transição a uma economia sustentável, sendo elas: i) o estabelecimento de uma macroeconomia sustentável; ii) a mudança de concepção sobre a maneira de se pensar a prosperidade; iii) e o respeito aos limites impostos pelo meio ambiente. Tais propostas visam a importantes mudanças no comportamento dos países, abandonando o objetivo de crescimento econômico, com foco exclusivamente quantitativo, para um diferente posicionamento voltado a uma nova cultura e lógica social com atingimento de um estado estacionário no uso material/energético.

Ainda para o mesmo autor, torna-se evidente que uma das maneiras para atingir tal finalidade são as inovações que aumentem a produtividade do uso de recursos naturais, bem como a mitigação de danos ambientais já provocados. A busca por tais inovações podem constituir uma importante forma de melhorar a competitividade dos negócios, dentro de uma concepção sustentável. Não se pode, contudo, considerar que somente as aplicações de tais inovações sejam a única forma de atingir os objetivos propostos, pois a elas devem-se somar mudanças políticas e sociais no comportamento econômico dos países e da própria sociedade. 


\subsection{Instrumentos econômicos}

Além de um redirecionamento dos fundamentos políticos e macroeconômicos faz-se necessária a adoção de instrumentos econômicos específicos para uma implementação eficaz do processo de reindustrialização sustentável.

Os principais instrumentos econômicos voltados à questão ambiental são: i) subsídios cruzados; ii) pagamentos por serviços ecossistêmicos; iii) isenção tributária; iv) sistemas de depósito e reembolso; v) taxas ambientais sobre a emissão de resíduos e poluição; vi) taxas florestais e vinculadas ao uso de recursos renováveis; vii) impostos ambientais vinculados à taxação convencional; viii) licenças comercializáveis; ix) rotulagens e certificações ambientais; $x$ ) seguros de responsabilidade (Castro, 1994; Cavalcanti, 2000; São Paulo, 2010).

Algumas análises podem ser feitas sobre os instrumentos mais comumente aplicados.

A taxação sobre a emissão de resíduos e poluição advém da proposição de Pigou de que os agentes a gerarem externalidades negativas devem pagar uma taxa a qual reflita os custos que impostos por eles a outros agentes. Para Krugman (2010), se o governo impõe uma taxa sobre a poluição, além de gerar uma receita aos cofres públicos, os poluidores saberão antecipadamente o preço que terão de pagar, porém o governo não saberá o quanto de poluição será gerado, o que pode gerar um rompimento do limiar de resiliência ecossistêmica ${ }^{6}$.

Ainda o mesmo autor afirma que, se o governo impõe limites via licenças comercializáveis, ele saberá a quantidade de poluição a ser gerada, porém os poluidores não saberão a que preço as emissões irão chegar. Ademais, as receitas geradas nesse tipo de instrumento são captadas pelas indústrias que participam da comercialização ${ }^{7}$.

O instrumento de subsídio cruzado visa a tributar ou oferecer benefícios a poluidores/usuários de forma progressiva, de acordo com as diferentes quantidades de recursos naturais utilizados, quantidade de energia elétrica consumida, tipos e quantidades de poluentes emitidos ou por quantidade e tipo de resíduos gerados, a fim de racionalizar a utilização desses recursos e o impacto ambiental gerado.

O pagamento por serviços ecossistêmicos parte do conceito de provedorreceptor em que o provedor de serviços ambientais a executar ações as quais

(6) De uma forma geral, resiliência ecossistêmica significa a capacidade do ecossistema em absorver choques e impactos de forma construtiva, ou seja, de uma forma que as perdas ainda possam ser recuperadas. Assim, grandes impactos ambientais podem romper essa capacidade de resiliência e tornarem-se irreversíveis.

(7) O instrumento de licenças comercializáveis é mais indicado para as empresas cujos custos de reestruturação para adaptarem-se às exigências ambientais são muito altos. 
favoreçam a conservação, ampliação ou restauração de serviços ecossistêmicos recebe do comprador ou beneficiário de tal serviço um valor que reflete o custo de oportunidade e manutenção do mesmo (São Paulo, 2010).

Um instrumento que passará a ser importante é o sistema de depósito e reembolso, por meio da aplicação da Política Nacional de Resíduos Sólidos, instituída pela Lei 12.305/2010 e regulamentada pelo Decreto Federal 7.404/2010. Assim, as empresas deverão adotar o processo denominado logística-reversa que, segundo Iaquinto (2011, p. 29), “compreende um conjunto de ações, procedimentos e meios destinados a viabilizar a coleta e a restituição dos resíduos sólidos ao setor empresarial para reaproveitamento", além disso, haverá uma responsabilidade compartilhada entre os setores público, privado e consumidores na aplicação do processo.

O mesmo autor ainda afirma que a logística reversa desenvolve-se em dois campos: o pós-venda, referente aos materiais que sequer foram consumidos, como no caso de desistências de compras e sobras de produtos em lojas e o pós-consumo, quando os produtos esgotaram suas vidas úteis. Para tanto, deverá ser estabelecida uma estrutura de logística integrada para o depósito e reembolso desses produtos, envolvendo produtores, agentes de transporte, instituições e consumidores.

A escolha do instrumento econômico a ser utilizado deve passar por uma adaptação a cada caso específico, podendo inclusive estabelecer uma solução híbrida, com a aplicação de dois ou mais instrumentos ao mesmo tempo ${ }^{8}$. O que se torna evidente é cada instrumento possuir seus pontos positivos, também negativos e sua aplicação gerar incertezas aos agentes.

Assim, o papel do Estado é primordial para diminuir as incertezas dos agentes e garantir o mercado no longo prazo, com regulamentações a respeito das aplicações e prioridades de cada instrumento, bem como seu direcionamento para incentivar o processo de reindustrialização sustentável.

Alguns pontos, entretanto, são de suma importância em tal caso, como: i) o papel indutor e pró-ativo do Estado; ii) articulações entre ministérios e secretarias de Estado, poderes, estados da federação, agentes privados, centros de pesquisa e sociedade civil organizada; iii) a institucionalização da Economia Verde (e, por conseguinte, da própria Indústria Verde); iv) estudos, planejamento e políticas de estímulo (São Paulo, 2010).

(8) Pode-se citar como solução híbrida o caso da água, em que se deveria determinar a cobrança pelo uso da água (taxa ao uso de recursos renováveis) e, também, um limite (via licenças comercializáveis) pela exploração de acordo com a capacidade de renovação do ciclo hidrológico. Evidente que neste último caso existem incertezas e, para tanto, deve-se prevalecer a prudência ecológica. 
Ainda segundo esse mesmo autor, o Programa das Nações Unidas para o Meio Ambiente (PNUMA) define a Economia Verde como um processo de reconfiguração de negócios e de infraestrutura de modo a obter melhores retornos em investimentos no capital humano e natural. Ao mesmo tempo, reduzem-se as emissões de gases de efeito-estufa, extraem-se e utilizam-se menos recursos naturais, gerando menor quantidade de resíduos e contribuindo para a diminuição das disparidades sociais ao criar novas oportunidades de negócios e empregos.

Dentro da concepção de Economia Verde, os segmentos mais dinâmicos seriam o de energias renováveis, pesquisa e desenvolvimento de tecnologias verdes, construção civil sustentável e ecologia industrial.

O último segmento citado, qual seja a ecologia industrial, ainda pouco discutido e implantado no Brasil, poderia ser um importante meio de estabelecimento da reindustrialização sustentável, pois, por meio dele, os fluxos de matéria e energia da atividade industrial passam a ser observados de modo sistêmico e em estreita ligação com os ecossistemas impactados no âmbito local, regional e global, incluindo ainda a influência nos fatores econômicos e sociais. Técnicas e metodologias de ecologia industrial envolveriam prevenção à poluição, produção mais limpa, análise do ciclo de vida do produto e simbiose industrial (São Paulo, 2010).

A simbiose industrial, por exemplo, seria uma técnica decisiva a ser aplicada na reindustrialização sustentável, pois envolve a transformação de resíduos de uma determinada empresa em insumos para outra(s) empresa(s). Com a implantação da Política Nacional de Resíduos Sólidos, a simbiose industrial ganharia importância, levando as empresas a estudarem de uma forma mais pormenorizada os impactos de seus resíduos e produtos ao final da vida útil, criando um mercado, sobretudo entre as indústrias. Assim, surgirão novas oportunidades de negócios ambientalmente corretos e diminuirão os custos de matérias-primas e demais insumos, tornando os produtos mais baratos e competitivos em mercados nacionais e internacionais.

Mais uma vez, torna-se importante salientar a necessidade de ação do Estado na integração das políticas ambientais no âmbito das políticas econômicas, bem como reestruturar o marco legal para uma melhor aplicação desse modelo de ecologia industrial ${ }^{9}$.

(9) Existe, no Comitê Interministerial de Acompanhamento da PNRS, o Grupo de Trabalho de Incentivos Fiscais e Desoneração Tributária que busca estudar e debater formas de alinhamento das políticas tributárias e suas diferenças entre estados para a melhor aplicação da PNRS. Cita-se, como exemplo, a medida adotada pelo governo federal que permite às empresas industriais fazerem jus a crédito presumido de IPI, na aquisição de resíduos sólidos para serem usados como matérias-primas na fabricação de seus produtos. (Iaquinto, 2011). Tal ação, entretanto, ainda é muito tímida para determinar um processo mais avançado de simbiose industrial, necessitando, portanto, de outros instrumentos mais eficazes. 


\subsection{Benefícios e oportunidades da reindustrialização sustentável}

O estabelecimento de uma política industrial direcionada a um processo de reindustrialização sustentável traria importantes benefícios e oportunidades à economia brasileira.

Estudo realizado pela Secretaria de Meio Ambiente do Governo de São Paulo (São Paulo, 2010) indicou algumas vantagens potenciais da Economia Verde para o estado que, se aplicada no âmbito nacional, poderia trazer importantes benefícios como:

- Possibilidade de crescimento do Valor de Transformação Industrial (VTI) por meio da indústria verde, dado o alto VTI de produtos como painéis solares fotovoltaicos, turbinas para geração de energia eólica, novos materiais e produtos e reestruturação das indústrias convencionais.

- Aumento da participação de modais energéticos renováveis conjugados com maior eficiência de utilização.

- Maior eficiência na indústria de construção civil por meio do uso de insumos minerais reciclados.

- Incorporação da questão ambiental nos programas de incentivo à inovação.

- Melhoria do acesso da indústria a materiais reciclados.

Para Rose e Kunze (2009), o Brasil apresenta oportunidades potenciais principalmente em áreas ligadas à: i) utilização de energias renováveis como cogeração de energia a partir da biomassa, exploração de pequenos rios e bacias e a energia eólica, ii) gestão de resíduos industriais por meio da simbiose industrial, iii) aumento da eficiência energética dentre outros.

Soma-se também a possibilidade de exploração sustentável da flora Amazônica para a produção de fármacos, oportunidade ainda pouco utilizada pelo Brasil; incentivos fiscais para veículos elétricos e híbridos; plano de infraestrutura que contribua para a redução da emissão de gases de efeito-estufa; incentivo à produção têxtil a partir de matéria-prima reciclada.

Conforme já especificado, quanto ao âmbito microeconômico das empresas, pode-se afirmar que a internalização da questão ambiental nos processos produtivos e decisórios não só provoca apenas aumento de custos, mas também promove uma série de benefícios que podem suplantar tais custos ("hipótese de Porter"). Lustosa (2003, p. 161), "evidencia que as inovações adotadas para cumprir com as regulamentações ambientais fazem com que as empresas utilizem seus insumos de modo mais produtivo, reduzindo custos e compensando os gastos com as melhorias ambientais." 
Para North (1992), os benefícios para empresa de uma produção sustentável podem ser divididos em econômicos e estratégicos e são relacionados conforme o Quadro 2.

Quadro 2

Benefícios da produção ambientalmente sustentável

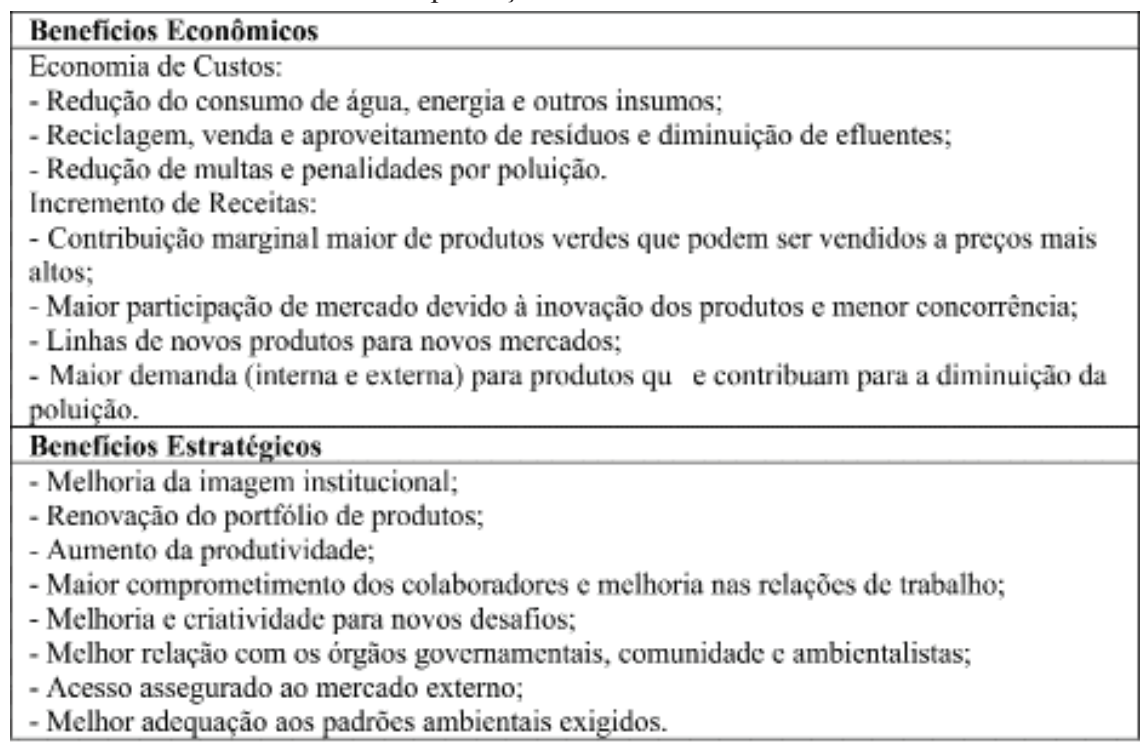

Fonte: North (1992).

Macroeconomicamente, a aplicação do processo de reindustrialização sustentável pode permitir uma melhoria na pauta de exportação brasileira com a participação de produtos de maior valor agregado e de geração de energia limpa e renovável, não ficando tão dependente apenas do mercado de commodities como ocorre nos dias atuais. Permite, inclusive, dinamizar as cadeias produtivas, incluindo fornecedores e prestadores de serviços, promovendo, assim, impactos positivos nos demais setores econômicos, por meio do processo de simbiose industrial.

Ainda nesse nível, pode-se citar, segundo Monteiro (2010), o fator salário, pois o setor industrial paga níveis mais altos de remuneração, o que contribui diretamente para o aumento da renda da massa assalariada, em especial, da classe média responsável por considerável fatia do consumo interno, além de colaborar para o aumento do trabalho formal.

\section{Considerações finais}

O presente artigo buscou apresentar uma proposta de reversão ao processo desindustrializante brasileiro por meio de uma reindustrialização que tenha a 
sustentabilidade ambiental como direcionador estratégico, a fim de se obter vantagem competitiva no mercado internacional.

Os principais países emergentes já determinaram sua estratégia competitiva, como exemplo, a China que optou pela produção de manufaturados e a Índia pelo mercado de tecnologia da informação e comunicação. O Brasil ainda não definiu seu direcionamento estratégico e continua extremamente dependente do mercado de commodities o que é muito complexo, visto serem produtos sem tanto valor agregado e cujos preços oscilam de modo contínuo, podendo provocar, no futuro, impactos na balança comercial brasileira.

O Brasil deveria usar de sua liderança em certos ramos sustentáveis como a produção energética e de sua disponibilidade de recursos naturais para redirecionar o processo industrial via uma política econômica que integre a questão ambiental e a necessidade de reindustrializar a economia, provocando, assim, nova dinâmica em seu processo produtivo e tornando-se um importante competidor internacional em uma área que tende a expandir no futuro.

Para tanto, conforme já especificado no desenvolvimento do trabalho, a ação do Estado é primordial como indutor e regulador do processo, bem como um dos principais financiadores do projeto, adotando uma política industrial bem estruturada para esse fim e conjugada com as demais políticas econômicas, principalmente, monetária e cambial.

O presente artigo também teve por objetivo intrínseco lançar uma discussão sobre reindustrialização sustentável, assim, novos trabalhos deverão surgir tratando das especificidades desse processo para cada segmento industrial específico, levando em consideração suas características próprias. O que não deve ocorrer é o país deixar mais uma vez que passe a oportunidade em um momento de recuperação econômica mundial e de sensibilização sobre a questão ambiental como direcionadora dos negócios e determinante da competitividade internacional.

\section{Referências bibliográficas}

CANO, W.; SILVA, A. L. G. Política industrial do governo Lula. Campinas: Unicamp. IE, jul. 2010. (Texto para Discussão). Disponível em: $<$ http://www.eco.unicamp.br/publicações/ textos >. Acesso em: 16 nov. 2010.

CASTRO, J. A. The internalization of external environmental costs and sustainable development. Switzerland: Unctad, mar. 1994. (Discussion papers, 81).

CAVALCANTI, R. N. Mineração e desenvolvimento sustentável: casos da CVRD. 1996. Tese (Doutorado em Engenharia Mineral)-Escola Politécnica da USP, São Paulo, 1996.

. Política ambiental. In: CAVALCANTTI, R. N. et. al. Administração ambiental. Especialização em engenharia ambiental, Departamento de Processos Químicos, Faculdade de Engenharia Química da Unicamp, 2000. 
COMIN, A. A desindustrialização truncada: perspectivas do desenvolvimento econômico brasileiro. 2009. 257 f. Tese (Doutorado em Ciências Econômicas)-Instituto de Economia, Unicamp, Campinas, 2009.

DALY, H. E..; FARLEY, J. Ecological economics: principles and applications. Washington DC: Island Press, 2004.

DIAS, C. Responsabilidade de todos. Desafios do desenvolvimento - IPEA, Brasília, ano 7, n. 61, p. $74-77$, maio/jun. 2010 .

FIGUEIREDO, P. N. O papel dos recursos naturais no crescimento do país. Conjuntura Econômica, Rio de Janeiro, v. 65, n. 7, p. 46-48, jul. 2011.

FREEMAN, C. The economics of hope: essays on technical change, economic growth and the environment. London; New York: Pinter Publishers, 1992.

GUIMARÃES, L. Indústria perde competitividade e "rombo" na balança do setor cresce. G1. São Paulo, 03 de nov. de 2010. Disponível em: < http://www.globo.com> Acesso em: 10 nov. 2010 .

IAQUINTO, K. Na natureza nada se cria, nada se perde, tudo se transforma. Conjuntura Econômica, Rio de Janeiro, v. 65, n. 6, p. 29-32, jun. 2011.

IEDI - Instituto de Estudos para o Desenvolvimento Industrial. Ocorreu uma desindustrialização no Brasil? [s.1.], nov. 2005.

. Comércio exterior hora de agir. Jan. 2011. Disponível em: <http://www.iedi. org.br/artigos/top/analise/analise iedi 20110120 comercio_exterior_hora_de agir.html $>$. Acesso em: 01 jun. 2011.

JACKSON, T. Prosperity without growth: the transition to a sustainable economy. Sustainable Development Commission, 2009.

KLEBER, K. O câmbio centraliza o debate econômico. Conjuntura Econômica, Rio de Janeiro, v. 64, n. 10, p. 40-45, out. 2010.

KRUGMAN, P. Building a green economy. The New York Times, New York, 05 apr. 2010.

LAPLANE, M. F.; SARTI, F. Prometeu acorrentado: O Brasil na indústria mundial no início do século XXI. In: CARNEIRO, R. (Org.). A supremacia dos mercados e a política econômica do Governo Lula. São Paulo: Editora Unesp, 2006, p. 299-320.

LAVORATTI, L. As exigências para crescer. Conjuntura Econômica, Rio de Janeiro, v. 64, n. 8, p. 24-33, ago. 2010.

LIMA, M. S. SP perde liderança entre exportadoras. Folha de S. Paulo, São Paulo, 25 out. 2010. Mercado, Caderno B, p. 3.

LUSTOSA, M. C. J. Industrialização, meio ambiente, inovação e competitividade. In: MAY, P. H.; LUSTOSA, M. C.; VINHA, V. da. Economia do meio ambiente. Rio de Janeiro: Campus, 2003. p. 155-172. 
LUSTOSA, M. C. J. Comércio internacional e meio ambiente: definição do padrão de especialização ambiental das exportações brasileiras. In: COELHO, A. B. et al.(Edit.). Recursos naturais e crescimento econômico. Viçosa, MG: Departamento de Economia Rural - UFV, 2008.

MERCADANTE, A. As bases do novo desenvolvimentismo no Brasil: análise do Governo Lula (2003-2010). Tese (Doutorado em Economia)-Instituto de Economia, Unicamp, Campinas, 2010.

MONTEIRO, S. Novo salto. Conjuntura Econômica, Rio de Janeiro, v. 64, n. 12, p. 26-34, dez. 2010.

NORTH, K. Environmental business management: an introduction. Genebra: International Labor Office (ILO), 1992.

OREIRO, J.L.; FEIJÓ, C. A. Desindustrialização: conceituação, causas, efeitos e o caso brasileiro. Revista de Economia Política, [s.1.], v. 30, n. 2, p. 219-232, abr./jun. 2010.

PORTUGAL JÚNIOR, P. S.; SILVA, T.T.; PORTUGAL, N. S.; PAIVA, L. R. Instrumentos certificadores e econômicos no gerenciamento ambiental: uma análise do Selo Verde Europeu para Mineração. In: SIMPÓSIO DE EXCELÊNCIA EM GESTÃO E TECNOLOGIA, SEGeT, 7, 2010, Resende - RJ. Anais eletrônicos... Disponível em: < $\underline{\text { http://www.aedb.br/ }}$ seget/artigos 10/218 Artigo\%20Instrumentos $\% 20$ certificadores $\% 20 \mathrm{e} \% 20$ economicos.pdf $>$. Acesso em: 22 jul. 2011.

REYDON, B. P.; CAVINI, R. A.; ESCOBAR, H. E.; FARIA, H. M. A competitividade verde enquanto estratégia empresarial resolve o problema ambiental? Campinas: Unicamp. IE, jul. 2007. (Texto para discussão). Disponível em: $<$ http://www.eco.unicamp.br/publicações/ textos >. Acesso em: 07 maio 2009.

ROSE, R.; KUNZE, T. (Edit.). Green technologies in Brazil: An overview of the sustainability market. São Paulo: AHK German Chamber of Industry and Commerce in Brazil and Roland Berger Strategy Consultants, 2009.

ROWTHORN, R.; RAMASUANY, R. Growth, trade and deindustrialization. IMF Staff Papers, [s.1.], v. 46, n. 1, 1999.

SÃO PAULO (Estado). Secretaria do Meio Ambiente - Coordenadoria de Planejamento Ambiental. Economia Verde: desenvolvimento, meio ambiente e qualidade de vida no Estado de São Paulo. CARVALHO, C. T. R. L. (coord.) São Paulo: SMA/CPLA, 2010.

SARTI, F.; HIRATUKA, C. Desenvolvimento industrial no Brasil: oportunidades e desafios futuros. Campinas: IE. Unicamp, jan. 2011. (Textos para Discussão, 187).

SOUZA, N. J. Desenvolvimento econômico. 4. ed. São Paulo: Atlas, 1999.

TREGENNA, F. Characterizing deindustrialization: an analysis of changes in manufacturing employment and output internationally. Cambridge Journal of Economics, [s.1.] v. 33, 2009.

VEIGA, J. E. As ondas longas do capitalismo industrial. In: ENCONTRO NACIONAL DE ECONOMIA, 2, 1997, São Paulo. Anais. Sociedade Brasileira de Economia Política, 1997. 